\title{
Simulation of Oil Production in a Fractured Carbonate Reservoir
}

\author{
Nora Cecilie Ivarsdatter Furuvik Britt M. E. Moldestad \\ Department of Process, Energy and Environmental Technology, University College of Southeast Norway, Norway, \\ \{nora.c.i.furuvik, britt.moldestad\}@usn.no
}

\begin{abstract}
$\mathrm{CO}_{2}$-EOR is an attractive method because of its potential to increase the oil production from matured oilfields, at the same time reduce the carbon footprint from the industrial sources. The field response to the $\mathrm{CO}_{2}$-EOR technique depends on the petrophysical properties of the reservoir. Carbonate reservoirs are characterized by low permeability and strong heterogeneity, causing significant amounts of water and $\mathrm{CO}_{2}$ to be recycled when $\mathrm{CO}_{2}$ is re-injected into the reservoir. Naturally fractured carbonate reservoirs have low oil production, high water production, early water breakthrough and high water cut. This study focuses on the oil production and the $\mathrm{CO}_{2}$ recycle ratio in naturally fractured carbonate reservoirs, including near-well simulations using the reservoir software Rocx in combination with OLGA. The simulations indicate that closing the fractured zone causes delayed water breakthrough and dramatically reduced water cut, resulting in improved oil recovery as well as lower production and separation costs.
\end{abstract}

Keywords: $\quad \mathrm{CO}_{2}$-EOR, fractured carbonate reservoirs, inflow control, near well simulation

\section{Introduction}

Deep geologic injection of supercritical carbon dioxide $\left(\mathrm{CO}_{2}\right)$ for enhanced oil recovery (EOR) plays an important role in the sequestration of $\mathrm{CO}_{2}$ to minimize the impact of $\mathrm{CO}_{2}$-emissions due to global warming (Ettehadtavakkol et al, 2014; Hill et al, 2013). $\mathrm{CO}_{2^{-}}$ EOR refers to the oil recovery technique where supercritical $\mathrm{CO}_{2}$ is injected into the oil reservoir to stimulate the oil production from depleted oilfields. The $\mathrm{CO}_{2}$ mixes with the stranded oil and change the oil property, making the immobile oil mobile and producible (Ettehadtavakkol et al, 2014).

The efficiency of the $\mathrm{CO}_{2}$-EOR technique greatly depends on the petrophysical properties of the reservoir (Ettehadtavakkol et al, 2014; Tarek, 2014). In carbonate reservoirs, the petrophysical properties generally are controlled by the presence and the distribution of naturally fractures. Fractures are high permeability pathways for fluid migration in a low permeability rock matrix (Fitch, 2010; Moore, 1989). Oil recovery from carbonate reservoirs with fractures are challenging compared to oil recovery from other reservoirs, as the fluids preferably will flow through the high permeable fractures. The result is poor sweep efficiency and potentially low oil recovery, due to very early water breakthrough (Haugen, 2010).

Most carbonate reservoirs are naturally fractured, causing significant amounts of water and $\mathrm{CO}_{2}$ to be produced together with the main stream from the production well during the $\mathrm{CO}_{2}$-EOR process. (Fitch, 2010; Ettehadtavakkol et al, 2014). For the oil companies this is both economic, operational and environmental challenging. High demands and rising oil prices has increased the focus on new inflow technology to improve oil recovery from low recovery oilfields (Tarek, 2014). The breakthrough of water and $\mathrm{CO}_{2}$ can be limited by installing Autonomous Inflow Control Valves (AICV) in the inflow zones in the well. The AICV will automatically shut off the production of water and $\mathrm{CO}_{2}$ from one specific zone in the well, but at the same time continue the production of oil from other zones. The AICV can replace the conventional Inflow Control Devices (ICD) installed in a well (Brettvik, 2013).

This study focuses on $\mathrm{CO}_{2}$-EOR in naturally fractured carbonate reservoirs, including simulations of oil production from an oil-wet reservoir. Both ICD and AICV completion were simulated in order to study the benefits of the AICV technology. The simulations are carried out using commercial reservoir simulation software.

\section{$2 \mathrm{CO}_{2}$-EOR}

$\mathrm{CO}_{2}$-EOR is a technique that involves injection of supercritical $\mathrm{CO}_{2}$ into underground geological formations, or deep saline aquifers. The goal is to revitalize matured oilfields, allowing them to produce additional oil. $\mathrm{CO}_{2}$ is highly soluble in oil and to a lesser extent in water. $\mathrm{As}^{\mathrm{CO}_{2}}$ migrates through the reservoir rock, it mixes with the residual oil trapped in the reservoir pores, enabling the oil to slip through the pores and sweep up in the flow from the $\mathrm{CO}_{2}$-injection well towards the recovery well. (Hill et al, 2013) The principle of $\mathrm{CO}_{2}$-EOR is shown in Figure 1.

When supercritical $\mathrm{CO}_{2}$ and oil mix, a complicated series of interactions occur wherein the mobility of the crude oil is increased. These interactions involve 
reduction in the interfacial tensions and the capillary pressure between the oil and the water phase. Injection of $\mathrm{CO}_{2}$ into the oil formation changes the oil physical properties in two ways, leading to enhanced oil recovery. First, the oil viscosity is reduced so that the oil flows more freely within the reservoir. Then, a process of dissolution occur thereby causing swelling of the oil, resulting in expansion in oil volume which means that some fluid have to migrate. The amount of swelling depends on the reservoir pressure and temperature, the hydrocarbon composition and the physical properties of the oil (Hill et al, 2013; Pasala, 2010, NRG Energy, 2014; Ghoodjani et al, 2011).

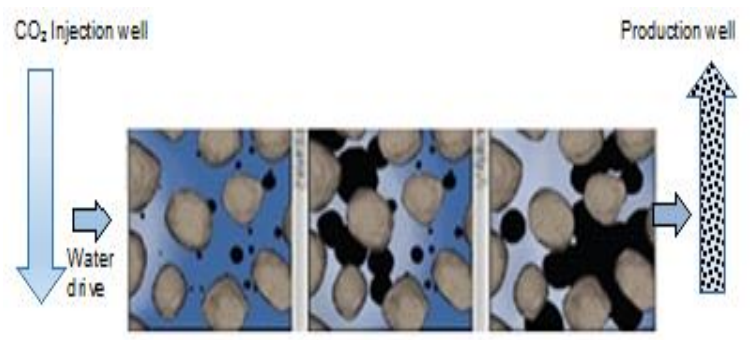

Figure 1. Principle of $\mathrm{CO}_{2}$-EOR (Oil and Gas 360, 2016).

\section{Carbonate reservoirs}

More than $60 \%$ of the world's oil resources occur in carbonate rocks (Fitch, 2010). Although carbonate reservoirs contain a majority of the oil reserves, only small amounts of the oil production worldwide come from these reservoirs (Fitch, 2010). Generally, carbonate reservoirs are characterized by complicated pore structures and strong heterogeneity. The heterogeneity of carbonate reservoirs is the result of a complex mineral composition and a complex rock texture. The heterogeneity is one of the main reasons causing low oil recovery from carbonates, as it contributes to highly variability in the petrophysical properties within small sections of the reservoir (Fitch, 2010; Moore, 1989).

\subsection{Petrophysical properties of carbonate reservoirs}

The petrophysical properties are controlled by the presence and the distribution of open fractures. Most carbonate reservoirs have a dual character of rock matrix and natural fractures. Fractures are discontinuities in the rock appearing as breaks in the natural sequence. The orientation of the fracture can be anywhere from horizontal to vertical, as illustrated in Figure 2. The fractured corridors exist in all scales, ranging from microscopic cracks to fractures of ten to hundreds of meters in width and height. This results in greatly variable permeability in carbonate reservoirs, from values less than $0.1 \mathrm{mD}$ in cemented carbonates to over $10000 \mathrm{mD}$ in fractures and have a considerable impact on oil production (Fitch, 2010; Moore, 1989).
Porosity is another important parameter affecting the oil recovery as it is a result of the secondary processes involving compaction and cementation of the sediments, and is controlled by the original grain shape and grain size distribution. Porosity in carbonate reservoirs varies from $1 \%-37 \%$ (Fitch, 2010).

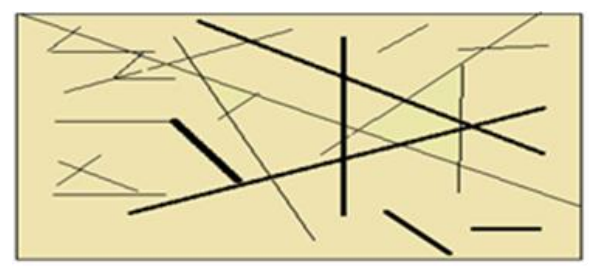

Figure 2. Fractures in reservoir.

Wettability of the reservoir describes the preference for the rock matrix to be in contact with one certain fluid phase over another. The reservoirs can be either waterwet or oil-wet (Satter et al, 2007). An oil-wet reservoir has higher affinity for the oil phase than for the water phase, oil will occupy the smaller pores and preferably stick to the grain surface in the larger pores. In oil-wet reservoirs, attractive forces between the rock and the fluid draw the oil into the smaller pores. While repulsive forces cause the water to remain in the center of the largest pores. The opposite condition is water-wet reservoir, in which the pore surface prefers contact with the water phase and water absorbs into the smaller pores. The wetting phase fluid often has low mobility, while the non-wetting fluid is more mobile and especially at large non-wetting phase saturations (Schlumberger, 2007; Ahmed, 2013, International Human Resources Development Corporation, 2016). A great majority of carbonate reservoirs tend to be oil-wet. Extensive research work on wettability for carbonate reservoir rocks confirms that carbonates exhibit significantly more oil-wet character than water-wet character. Performed contact angle measurements show that $15 \%$ of carbonates are strongly oil-wet $\left(\theta=160^{\circ}-180^{\circ}\right), 65 \%$ are oil-wet $\left(\theta=100^{\circ}-160^{\circ}\right), 12 \%$ are intermediate-wet and $8 \%$ are water-wet (Esfahani et al, 2004). Evaluations of wettability for the carbonate rock samples, using relative permeability curves and Amott tests conclude that the carbonate reservoirs investigated ranges from intermediate-wet to oil-wet (Esfahani et al, 2004). Figure 3 illustrates the difference between a water-wet and an oil-wet reservoir rock.

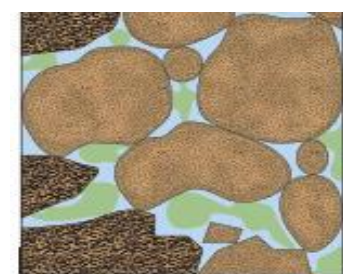

Water-wet reservoir

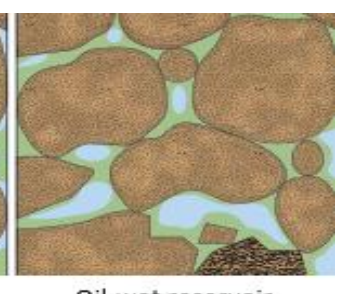

Oil-wet reservoir
Figure 3. Wetting in pores (Schlumberger, 2007). 
Presumed petrophysical properties of carbonate reservoirs are presented in Table 1.

Table 1. Petro physical properties of carbonate reservoirs (Fitch, 2010; Moore, 1989).

\begin{tabular}{|l|l|l|l|}
\hline Porosity & Permeability & $\begin{array}{l}\text { Permeability } \\
\text { in fracture }\end{array}$ & Wettability \\
\hline $0.01-0.3$ & $0.7-130 \mathrm{mD}$ & Large & $\begin{array}{l}\text { Intermedia } \\
\text { te-wet to } \\
\text { strongly } \\
\text { oil-wet }\end{array}$ \\
\hline
\end{tabular}

\section{2 $\mathrm{CO}_{2}$-EOR in carbonate reservoirs}

Use of supercritical $\mathrm{CO}_{2}$ for EOR stimulates oil production from low recovery oilfields, simultaneously contributing to minimizing the impact of $\mathrm{CO}_{2}$-emission to the atmosphere. The injected $\mathrm{CO}_{2}$ remains trapped in the underground geological formations, as much of the $\mathrm{CO}_{2}$ is replacing the oil and water in the pores (NRG Energy, 2014).

Some of the world's largest remaining oil reserves are found in oil-wet, fractured carbonate reservoirs. The oil production performance from these reservoirs is nearly half the production from other reservoirs, whereas the $\mathrm{CO}_{2}$ utilization is about $60 \%$ less (Ettehadtavakkol et al, 2014; Fitch, 2010). $\mathrm{CO}_{2}$-EOR in carbonate reservoirs poses great challenges to the oil industry as it is strongly linked to the relationship between the fractures and the rock matrix. Because fractures may exhibit permeabilities that are several orders of magnitude higher than the permeability of the rock matrix, the $\mathrm{CO}_{2}$ may channel into the high permeable fractures and thereby not contribute to EOR.

\section{Simulations}

The near-well simulations of $\mathrm{CO}_{2}$-injection into the carbonate reservoir were carried out using the commercial reservoir simulation software Rocx, in combination with OLGA. The OLGA software is the main program, but several additional modules are developed to solve specific cases. The geometry for the simulated reservoir is $0.5 \mathrm{~m}$ in length, $96 \mathrm{~m}$ in width and $50 \mathrm{~m}$ in height. 3 grid blocks are defined in $\mathrm{x}$-direction, 25 in y-direction and $10 \mathrm{in} \mathrm{z-direction.} \mathrm{The} \mathrm{radius} \mathrm{of} \mathrm{the}$ wellbore is $0.15 \mathrm{~m}$. The well is located $35 \mathrm{~m}$ from the bottom, indicated as a black dot in Figure 4.

The reservoir is divided into three zones in $\mathrm{x}$-direction. A constant porosity of 0.15 is used in the entire reservoir. A permeability of $4000 \mathrm{mD}$ is set in the second zone, and a permeability of $40 \mathrm{mD}$ is set in the first and the third zone. The second zone represents the fractured part, thus the permeability is set much higher in this zone compared to the two other zones. The temperature is maintained constant at $76^{\circ} \mathrm{C}$ and the waterdrive pressure from the bottom of the reservoir is $176 \mathrm{bar}$, the wellbore pressure is set to 130 bar.

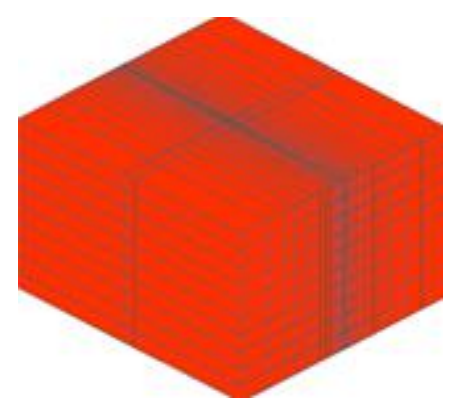

Figure 4. Grid and geometry of the simulated reservoir.

The reservoir and fluid properties for the simulations carried out are presented in Table 2.

Table 2. Reservoir and fluid properties for the specific simulations.

\begin{tabular}{|l|l|}
\hline Properties & Value \\
\hline Oil viscosity & $10 \mathrm{cP}$ \\
\hline $\begin{array}{l}\text { Reservoir pres } \\
\text { sure }\end{array}$ & $176 \mathrm{bar}$ \\
\hline Reservoir temperature & $76^{\circ} \mathrm{C}$ \\
\hline Oil specific gravity & 0.8 \\
\hline Porosity & 0.15 \\
\hline $\begin{array}{l}\text { Permeability first zone } \\
\text { (x-y-z direction) }\end{array}$ & $40-40-20 \mathrm{mD}$ \\
\hline $\begin{array}{l}\text { Permeability second } \\
\text { zone (x-y-z direction) }\end{array}$ & $4000-4000-2000 \mathrm{mD}$ \\
\hline $\begin{array}{l}\text { Permeability third zone } \\
\text { (x-y-z direction) }\end{array}$ & $40-40-20 \mathrm{mD}$ \\
\hline Wellbore pressure & $130 \mathrm{bar}$ \\
\hline
\end{tabular}

The module Rocx is connected to OLGA by the nearwell source component in OLGA, which allows importing the file created by Rocx. In order to get a simulation of the complex system including valves and packers, OLGA requires both a "Flowpath" and a "Pipeline" as shown in Figure 5.

In the simulations, the "Flowpath" represents the pipe and the "Pipeline" represents the annulus. The annulus is the space between the pipe and the rock, as presented in (Schlumberger, 2007).
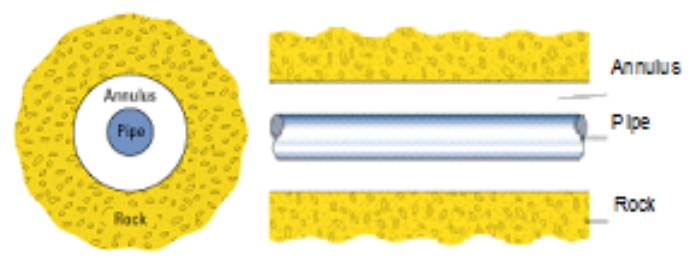

Figure 5. A schematic of the pipe and the annulus. (Schlumberger, 2007). 

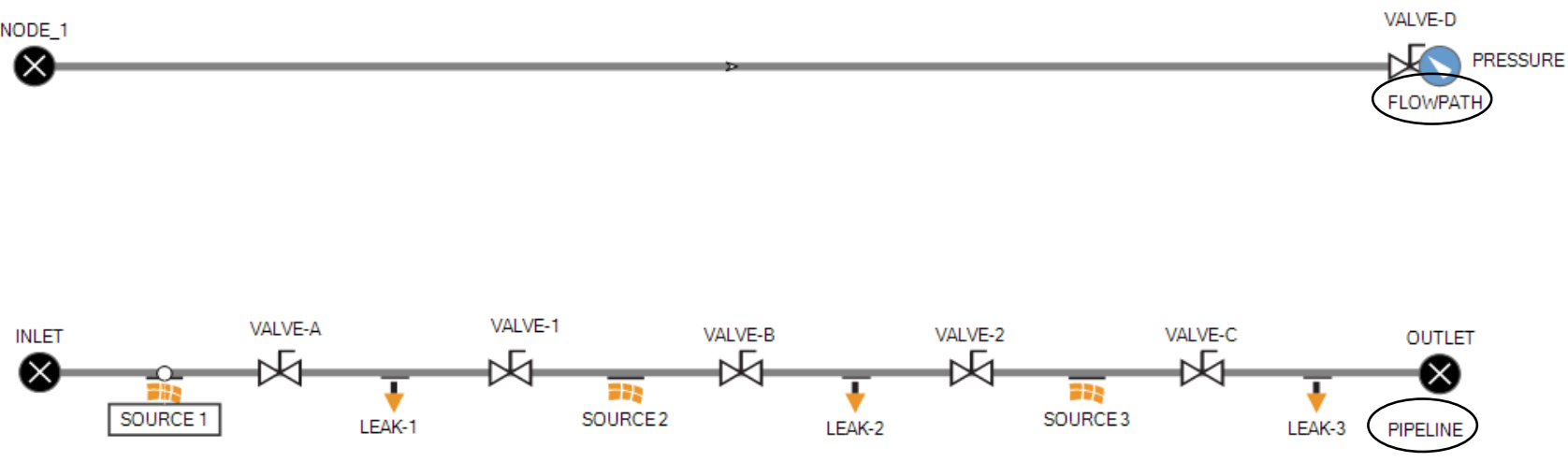

Figure 6. OLGA study case for the performed simulations.

Figure 7 illustrates how the "Flowpath" is divided into six equal sections. The sources implemented in the "Pipeline" are connected to the boundaries in Rocx, and indicate the inflow from the reservoir into the annulus. the leaks indicate the inflow from the annulus into the pipe, through the control valves A, B and C. The packers are simulated as closed valves and are installed to isolate the different production zones in the well.

In the simulations, the packers divide the "Pipeline" into three zones. The inflow from Source-1 goes from section one in the annulus and enters the pipe in section two. Similarly, for the flow in the production zones two and three.

\subsection{Relative permeability curves}

The simulation software Rocx generates the relative permeability curves for oil $\left(\mathrm{K}_{\mathrm{ro}}\right)$ and water $\left(\mathrm{K}_{\mathrm{rw}}\right)$. The calculations are based on the Corey correlation, a power law relationship with respect to water saturation. The model is derived from capillary pressure data and is widely accepted as a good approximation for relative permeability curves in a two-phase flow. The required input data is limited to the irreducible water saturation $\left(\mathrm{S}_{\mathrm{wc}}\right)$ and the residual oil saturation $\left(\mathrm{S}_{\mathrm{or}}\right)$, and their corresponding relative permeabilities (Tangen, 2012):

$$
\begin{aligned}
& K_{r w}=K_{r w o c}\left(\frac{S_{w}-S_{w c}}{1-S_{w c}-S_{o r}}\right)^{n_{w}} \\
& K_{r o}=K_{\text {rowc }}\left(\frac{1-S_{w}-S_{o r}}{1-S_{w c}-S_{o r}}\right)^{n_{o w}}
\end{aligned}
$$

Where $S_{w c}$ defines the maximum water saturation that a reservoir can retain without producing water, and $S_{\text {or }}$ refers to the minimum oil saturation at which oil can be recovered by primary and secondary oil recovery. $\mathrm{K}_{\text {rwoc }}$ is the relative permeability of the water at the residual oil saturation, and $\mathrm{K}_{\text {rowc }}$ is the relative permeability of oil at the irreducible water saturation. $n_{w}$ and $n_{\text {ow }}$ are the Corey coefficients for water and oil respectively. The coefficients are functions of the pore size distribution in the reservoir and are therefore reservoir specific. The Corey coefficients strongly influence the relative permeability curves, as the relative permeability changes when the pore-geometry change. Typical values for the Corey coefficient for an oil-wet reservoir are $\mathrm{n}_{\mathrm{w}}=2-3$ and $\mathrm{n}_{\mathrm{ow}}=6-8$.

To simulate $\mathrm{CO}_{2}$-injection into the reservoir, it was necessary to correlate for the effects of $\mathrm{CO}_{2}$ to the

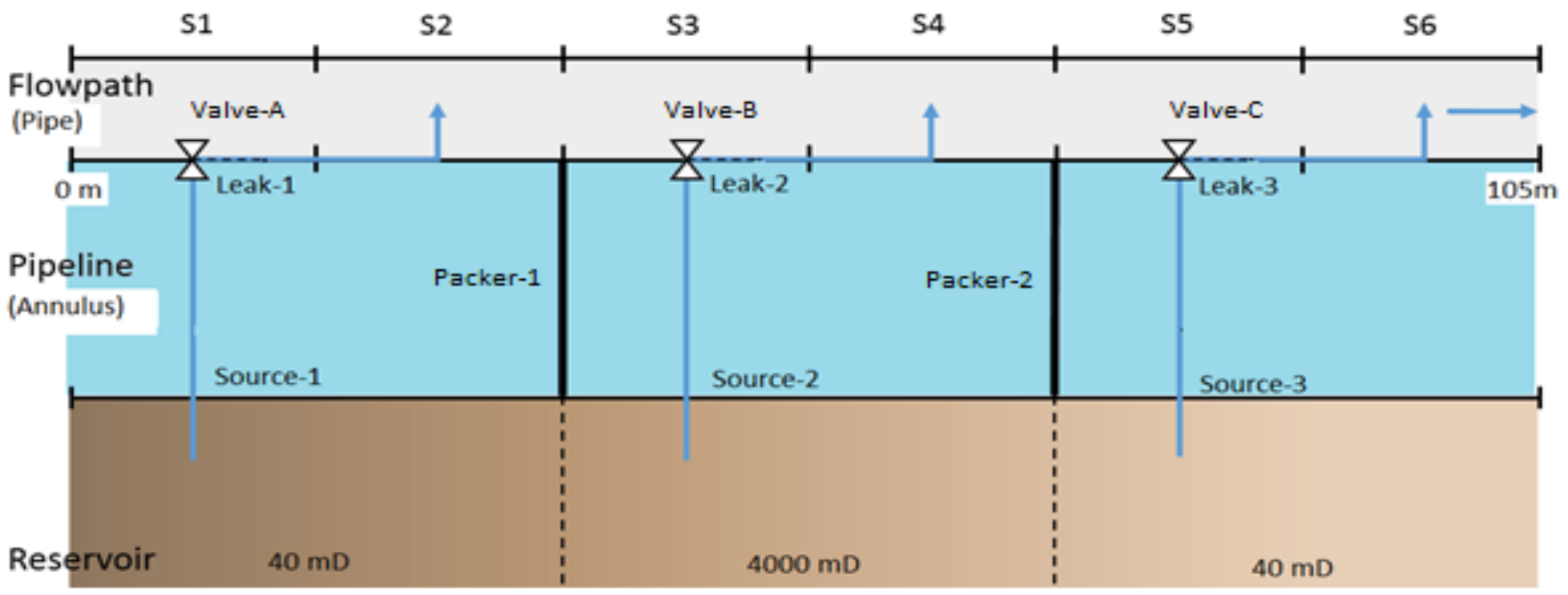

Figure 7. The near-well simulation in OLGA. 
relative permeability curves. $\mathrm{CO}_{2}$-injection reduces the interfacial tension and the oil viscosity, and causes oil swelling. Based on these parameters, the following relations was implemented to calculate the Corey's exponents and the residual oil saturation for simulation with $\mathrm{CO}_{2}$-injection (Ghoodjani et al, 2011; Tangen, 2012):

$$
\begin{aligned}
& n_{\text {ow }}\left(\mathrm{CO}_{2}-\text { injection }\right)=0.568951 \cdot n_{o w} \\
& S_{\text {or }}\left(\mathrm{CO}_{2}-\text { injection }\right)=0.754288 \cdot S_{o r}
\end{aligned}
$$

The relative permeability curves for the performed simulations are generated in Rocx, using the parameters listed in Table 3.

Table 3. Relative permeability data for the specific simulations.

\begin{tabular}{|l|l|l|l|l|l|}
\hline$S_{w c}$ & $S_{o r}$ & $K_{\text {rowc }}$ & $K_{r w o c}$ & $n_{w}$ & $n_{o w}$ \\
\hline 0.1 & 0.1 & 1 & 0.75 & 3 & 3.4 \\
\hline
\end{tabular}

Figure 8 shows the implemented relative permeability curves for the simulations. The green lines represent the relative permeability of oil $\left(\mathrm{K}_{\mathrm{ro}}\right)$ and the blue lines represent the relative permeability of water $\left(\mathrm{K}_{\mathrm{rw}}\right)$. Initially, when the water saturation is equal to the critical water saturation $\left(\mathrm{S}_{\mathrm{w}}=\mathrm{S}_{\mathrm{wc}}\right)$ the injected $\mathrm{CO}_{2}$ does not contact fully with the oil. As oil saturation decreases, the movement of oil becomes more difficult and the injected $\mathrm{CO}_{2}$ will improve the oil flow by lowering interfacial tension and the oil viscosity. The $\mathrm{CO}_{2}$-injection may lead to reduced trapped oil and lower residual oil saturation by swelling mechanism.

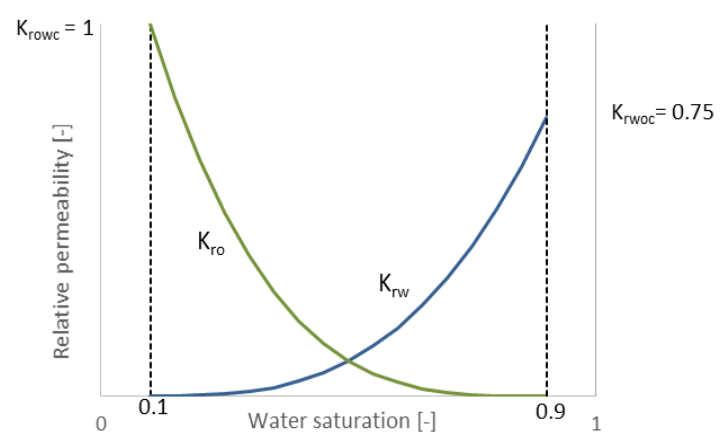

Figure 8. Relative permeability curves.

\subsection{Input to OLGA and Rocx}

The simulations were carried out for an oil-wet carbonate reservoir with fracture. Two different cases were simulated. Both cases include the relative permeability curves seen in Figure 8 and the reservoir and the fluid properties listed in Table 2. In Case 1, all control valves A, B and C are fully open. In Case 2 the control valve $\mathrm{A}$ and $\mathrm{C}$ are open, while control valve $\mathrm{B}$ is kept closed. This is to study how closing the fractured zone will affect the oil production and the $\mathrm{CO}_{2}$-recycle ratio in the reservoir. The simulations where run for 400 days. Detailed specifications for the simulations are listed in Table 4.

Table 4. Input for the performed simulations.

\begin{tabular}{|l|l|l|l|l|l|}
\hline Case & $\begin{array}{l}\text { Data } \\
\text { input to } \\
\text { Rocx }\end{array}$ & $\begin{array}{l}\text { Relative } \\
\text { perm. } \\
\text { curve }\end{array}$ & $\begin{array}{l}\text { CO2- } \\
\text { injection }\end{array}$ & $\begin{array}{l}\text { Position } \\
\text { Valve A } \\
\text { and } \\
\text { Valve C }\end{array}$ & $\begin{array}{l}\text { Position } \\
\text { Valve B }\end{array}$ \\
\hline 1 & $\begin{array}{l}\text { See } \\
\text { Table 2 }\end{array}$ & $\begin{array}{l}\text { See } \\
\text { Figure 9 }\end{array}$ & Yes & Open & Open \\
\hline 2 & $\begin{array}{l}\text { See } \\
\text { Table 2 }\end{array}$ & $\begin{array}{l}\text { See } \\
\text { Figure 9 }\end{array}$ & Yes & Open & Closed \\
\hline
\end{tabular}

\section{Results}

Produced water is the largest by-product associated with the oil production. The oil industry aim for new inflow control technology to shut off production from highly fractured zones when water breakthrough occur, and thereby be able to utilize the benefits from $\mathrm{CO}_{2}$-EOR . To simulate the closing of the fractured zone in Case 2, Autonomous Inflow Control Valves (AICV) replace the conventional Inflow Control Devices (ICD) in the well. The AICV completely stops the production from a specific production zone when it starts to produce water and/or gas along with the oil. The oil production from the well will continue from the other production zones in the reservoir. Figure 8 and Figure 9 shows the accumulated oil and water production respectively. The orange lines represent Case 1 and the black lines represent Case 2. Both cases simulate injection of $\mathrm{CO}_{2}$ into the reservoir, thus simulates $\mathrm{CO}_{2}$ displacing the oil. Assuming that the injected $\mathrm{CO}_{2}$ completely dissolve in the water phase, water is considered as carbonated water in the following results. The consequence with injection of $\mathrm{CO}_{2}$ into fractured reservoirs is that the carbonated water and $\mathrm{CO}_{2}$ moves through the fractures and directly into the production well, without being distributed in the reservoir. Large amounts of $\mathrm{CO}_{2}$ will in that case be recycled and will not contribute to EOR.

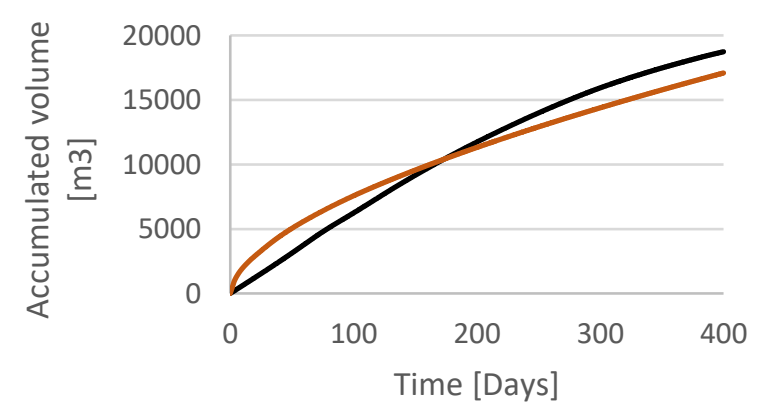

Figure 8. Accumulated oil volume. 


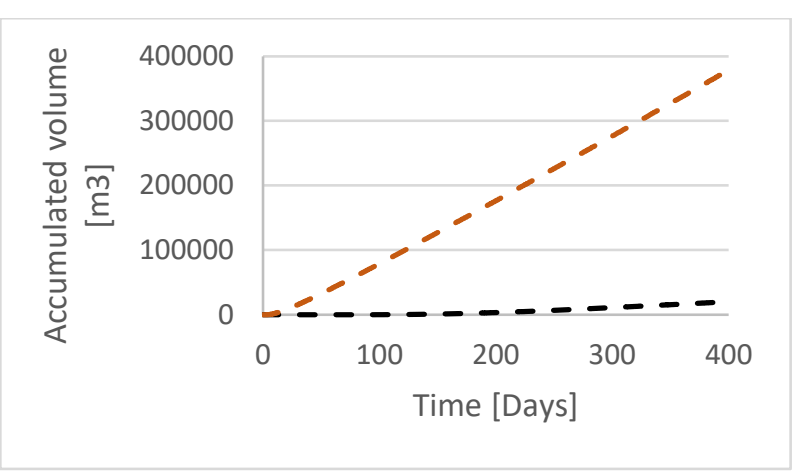

Figure 9. Accumulated water volume.

The large volume flow of carbonated water produced in Case 1 is due to no restrictions for the fluids to flow through the fractured zone in the reservoir, consequently most of the oil and carbonated water are produced from the second zone in this case. This is seen more clearly in Figure 10, where the total liquid flowrate in the different sections in the pipe is displayed. The total liquid flow includes the volume of oil, water and $\mathrm{CO}_{2}$. The orange line represents Case 1 and the black line represents Case 2.

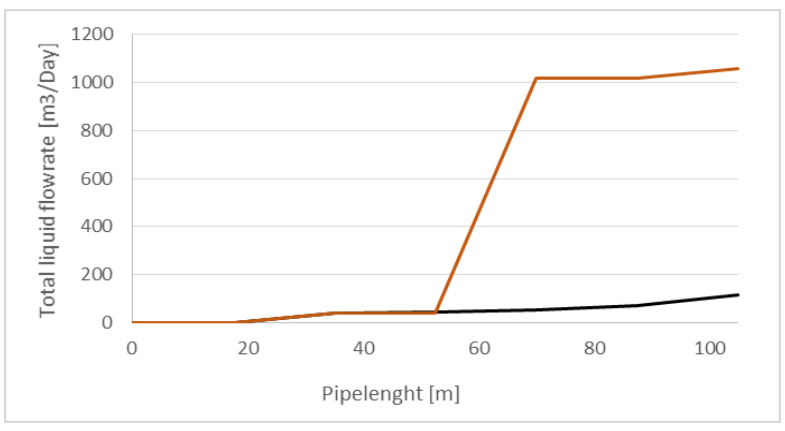

Figure 10. Total liquid flowrate along the pipe.

As seen from the figure, the major part of the total liquid volume is produced in the fractured part of the reservoir in Case 1, as it enters the pipe in section 4. For Case 2, the total liquid flowrate increases along with the pipeline, but the inflow from the annulus to the pipe occurs mainly in section 2 and section 6. This is as expected since these sections represent the first and the third production zone in the reservoir. In section 1, 3, 4 and 5 the total liquid flowrate is constant, this is due to no inflow from the annulus into the pipe in these sections, as the control valve in the second production zone is closed.

Fractured carbonate reservoirs are a major challenge for the oil industry using $\mathrm{CO}_{2}$-EOR. The low permeability and the high heterogeneity result in high production rate of water and $\mathrm{CO}_{2}$, mainly through the fractured zone. By chocking the high permeability zone, the oil and water production is reduced. On the second hand it delays the water breakthrough, which in turn results in decreased water cut. The water cut is the defined as the ratio of water to the total liquid, and expresses the amount of water produced along with the oil. Figure 11 shows the water cut during the whole simulation, the orange line represent Case 1 and the black line represent Case 2.

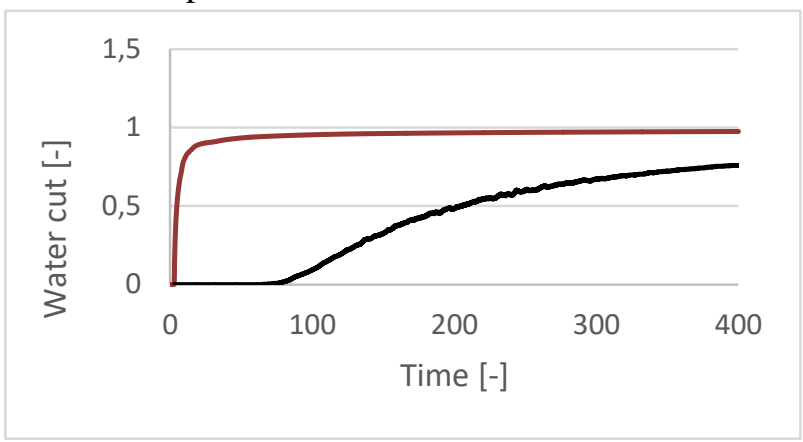

Figure 11. Water cut.

Carbonated water and $\mathrm{CO}_{2}$ produced along with the oil cause economic, operational and environmental difficulties for the oil industry. Treatment of the produced water faces challenges resulting in necessity for expanding the capacity of water separation and facilities for handling the large volumes of carbonated water and $\mathrm{CO}_{2}$. The high heterogeneity of carbonates is the main reason for the low oil recovery from these reservoirs. Water flows more easily through the fractured zone compared to the oil, resulting in very early water breakthrough and thereby high water and low oil flowrate. The results from the performed simulations are summarized in Table 5.

Table 5. Results from Case 1 and Case 2.

\begin{tabular}{|l|l|l|l|l|}
\hline Case & $\begin{array}{l}\text { Accumulated } \\
\text { oil volume } \\
{[\mathrm{m3}]}\end{array}$ & $\begin{array}{l}\text { Accumulated } \\
\text { water } \\
\text { volume [m3] }\end{array}$ & $\begin{array}{l}\text { Water } \\
\text { breakthrough } \\
{[\text { day] }}\end{array}$ & $\begin{array}{l}\text { Water } \\
\text { cut } \\
{[-]}\end{array}$ \\
\hline 1 & 17000 & 355500 & 2.9 & 0.975 \\
\hline 2 & 18700 & 20100 & 64 & 0.725 \\
\hline
\end{tabular}

As seen, closing the fractured zone in the reservoir is advantageous to achieve improved oil quality as well as lower production and separation costs. The water cut in Case 1 is 0.975 after 400 days of simulation, meaning that $97.5 \%$ of the total liquid volume is carbonated water and $\mathrm{CO}_{2}$. The high value for the water cut results in low quality oil and large amounts of carbonated water and $\mathrm{CO}_{2}$ to be removed subsequently. Another problem with fractures is decreased recovery due to early breakthrough of carbonated water in the well. When this occurs the carbonated water will be the dominating fluid and reduce the production of oil. At a certain point the production will no longer be profitable and the well may be abandoned even though a large amount of oil is still left in the reservoir. 


\section{Conclusions}

The objective of this work was to study $\mathrm{CO}_{2}$-EOR in a fractured carbonate reservoir. The study included nearwell simulations of oil production, using the reservoir software Rocx in combination with OLGA. $\mathrm{CO}_{2}$-EOR in fractured carbonate reservoirs gives low oil production, high water production, early water breakthrough and high water cut. The enormous amounts of water produced result in challenges regarding the necessity for expanding the capacity of water separation and facilities for handling the large volumes of carbonated water and $\mathrm{CO}_{2}$.

Fractures in the reservoir are a major problem for the oil industry using $\mathrm{CO}_{2}$-EOR. Water breakthrough occurs after only 2.9 days in a fractured reservoir and the water cut is $97.5 \%$ after 400 days of production. Due to the very early breakthrough of water, significant amounts of the injected $\mathrm{CO}_{2}$ will be recycled with the produced water. The simulations indicate that $\mathrm{CO}_{2-}$ injection into a carbonate reservoir in combination with closing the fractured zone causes delayed water breakthrough and dramatically reduced water cut, resulting in improved oil quality, longer lifetime for the well as well as lower production and separation costs.

\section{References}

K. Ahmed. $\mathrm{CO}_{2}$ injeksjon for $\phi k t$ oljeutvinning $i$ kalk. Masteroppgave i reservoarfysikk, Universitet i Bergen: Institutt for fysikk og teknologi, 2013.

M. Brettvik. Experimental and computational study of $\mathrm{CO}_{2}$ for EOR and secure storage reservoirs. Master Thesis, Telemark University College, Faculty of Technology, 2013.

M. R. Esfahani and M. Haghigi. Wettability evaluation of Iranian carbonate formations. Journal of Petroleum Science Engineering, 92(2-4): 257-265, 2004.

A. Ettehadtavakkol, L. W. Lake and S. L Bryant. $\mathrm{CO}_{2}$-EOR and storage design optimization. International Journal of Greenhouse Gas Control, 25: 79-92, 2014.

P. J. R. Fitch. (2010). Heterogeneity in the petrophysical properties of carbonate reservoirs. Doctor of philosophy, The University of Leicester, Department of Geology, 2010.

E. Ghoodjani and S. H. Bolouri. Experimental study and calculation of $\mathrm{CO}_{2}$-oil relative permeability, 53-(2): 123 131, 2011. Iran: Petroleum \& Coal Sharif University of Technology and Shahid Bahonar University. ISSN 13377027.

A. Haugen. Fluid Flow in Fractured Carbonates: Wettability Effects and Enhanced Oil Recovery. PhD-dissertation, Department of Physics and Technology, University of Bergen, Norway, 2010.

B. Hill, S. Hovorka and S. Melzer. Geologic carbon storage through enhanced oil recovery. Energy Procedia, 37: 68086830, 2013. USA, Elsevier Ltd.

International Human Resources Development Corporation. IPIMS, e-learning for the Upstream Petroleum Industry, Irreducible water: www.ihrdc.com/els/ipims-
demo/t26/offline_IPIMS_s23560/resources/data/G4108.ht m, 02.02.2016.

C. H. Moore. Carbonate Diagenesis and Porosity, 46, USA, Elsevier Science Publishers B.V. 1989. ISBN: 0-44487415-1.

NRG Energy. $\mathrm{CO}_{2}$ Enhanced Oil Recovery. NRG Fact Sheet, Texas: NRG Energy Inc., Available from: http://www.nrg.com/documents/business/pla-2014-eor.pdf, 2014.

Oil and Gas 360. Enhanced Oil Recovery Can Reduce World's Carbon Emissions: Western Governors, Available from:http://www.oilandgas360.com/enhanced-oilrecovery-can-reduce-worlds-carbon-emissions-westerngovernors, 02.02.2016.

S. M. Pasala. $\mathrm{CO}_{2}$ displacement mechanisms: Phase equilibria effects and Carbon dioxide sequestration studies. Doctor of Philosophy, University of Utah: Department of Chemical Engineering, 2010.

A. Satter, G. M. Iqbal and J. L. Buchwalter. Practical Enhanced Reservoir Engineering, Assisted with Simulation Software. USA, PennWell Corporation. ISBN-13: 987-159370-056-0. ISBN-10: 1-59370-056-3, 2007.

Schlumberger. Fundamentals of Wettability. Oilfield Review, 2(19): 66-71, 2007.

M. Tangen. Wettability Variations within the North Sea Oil Field Frøy. Master Thesis, Norwegian University of Science and Technology, Department of Petroleum Engineering and Applied Geophysics, 2012.

T. A. Tarek. Petrophysical characterization of the effect of Xanthan gum on drainage relative permeability characteristics using synthetic unconsolidated core plugs. Master of Petroleum Engineering, Dalhousie University, Halifax, Faculty of Engineering, 2014. 